\title{
Women's groups' perceptions of neonatal and infant health problems in rural Malawi
}

\section{Rosato $\mathbf{M}^{1}$, Lewycka $\mathbf{S}^{1}$,Mwansambo $\mathrm{C}^{2}$, Kazembe $\mathbf{P}^{\mathbf{3}}$, Costello $\mathbf{A}^{1}$}

1. UCL Institute of Child Health

2.Kamuzu Central Hospital

3. Baylor-Abbort Clinical Centre of Excellence

\begin{abstract}
Aims

To present the perceptions of women in rural Malawi regarding the health problems affecting neonates and infants and to explore the relevance of these perceptions for child health policy and strategy in Malawi.
\end{abstract}

\section{Methods}

Women's groups in Mchinji district identified newborn and infant health problems (204 groups, 3484 women), prioritised problems they considered most important (204 groups, 3338 women) and recorded these problems on monitoring forms. Qualitative data was obtained through 6 focus-group discussions with the women's groups and 22 interviews with individuals living in women's group communities but not attending groups.

\section{Results}

Women in Malawi do not define the neonatal period according to any epidemiological definition. In order of importance they identified and prioritised the following problems for newborns and infants: diarrhoea, infection, preterm birth, tetanus, malaria, asphyxia, respiratory tract infection, hypothermia, jaundice, convulsions and malnutrition.

\section{Conclusion}

This study suggests that women in rural Malawi collectively have a developed understanding of neonatal and infant health problems. This makes a strong argument for the involvement of lay people in policy and strategy development and also suggests that this capacity, harnessed and strengthened through community mobilisation approaches, has the potential to improve neonatal and infant health and reduce mortality.

\section{Introduction}

Malawi has a neonatal mortality rate of 27 per 1,000 live births, an infant mortality rate of 76 per 1,000 live births and an under-five mortality rate of 111 per 1,000 live births. ${ }^{1}$

Since 1990, Malawi has made progress towards achieving Millennium Development Goal (MDG) four of reducing under-five mortality by two-thirds by 2015, but like other countries in sub-Saharan Africa, the progress has been insufficient. ${ }^{2}$ It is unlikely that Malawi will achieve the target through current policies and strategies.

Amongst other strategies, Malawi is turning towards community mobilisation, in search of effective approaches for improving child health and reducing mortality. ${ }^{3}$ These approaches seek to harness and strengthen the collective capacities that exist in communities and use them to take control of their health. Community mobilisation is defined as "a capacity-building process through which community individuals, groups, or organizations plan, carry out, and evaluate activities on a participatory and sustained basis to improve their health and other needs, either on their own initiative or stimulated by others".4

Community mobilisation approaches, in particular those employing women's groups as the catalyst for mobilisation, are effective at reducing neonatal mortality. ${ }^{5,}{ }^{6}$ Two cluster randomised controlled trials of similar interventions are currently underway in four

districts in Malawi (Mchinji under MaiMwana Project and Lilongwe, Kasungu and Salima under MaiKhanda Project). The development of community mobilisation policies and strategies for child health in Malawi will benefit from the findings of these trials but also from an understanding of the perceptions of communities themselves about child health. These perceptions can provide information to ensure policies and strategies are feasible, appropriate and accessible. In addition, they can provide information about the capacities that already exist in communities and which when strengthening can empower communities to take control of their own health.

Medical professionals are often skeptical about what communities know and understand of their health problems, especially where literacy and educational levels are low. They might question whether women in the community are 'right' about the health problems they identify and whether they correlate with epidemiological patterns observed. The aim of this paper is to challenge these views and present the perceptions of women in Mchinji district in Malawi about the neonatal and infant health problems that exist in their communities. The implications of these findings for child health policy and strategy will be discussed.

\section{Methods}

\section{Setting}

Malawi has a population of 13 million people, a gross national product per person of $\$ 190$ and a life expectancy for women of 46 years $^{1,7,8}$ The total fertility rate is 6.0 children per woman and female literacy is 62\%. ${ }^{1}$ Mchinji District is in the central region of Malawi on the border with Zambia and Mozambique and has a population of approximately 450,000 people. $^{7}$ The main ethnic group in the district is Chewa and the district has one district hospital, four rural hospitals, seven health centres that provide maternity care and three health centres that provide antenatal care. There are approximately 750 people per hospital bed.

MaiMwana Project was established as a research and development project in Mchinji District in 2003. The project is a collaboration between the Malawi Ministry of Health and the UCL Centre for International Health and Development seeking to improve mother and child health and reduce mortality through two community-based interventions (women's groups, a community mobilisation intervention; and volunteer infant care counselling, a health education intervention). It is also assessing the effectiveness of

these interventions through a large scale cluster randomised controlled trial and the accessibility, appropriateness and 
feasibility of these interventions through an integrated process evaluation. MaiMwana Project has ethical approval from the Malawi National Health Sciences Research Committee.

\section{Methods and sample}

Quantitative data was collected through the monitoring system of the women's group intervention. As described elsewhere the groups followed a four phase (problem identification and prioritisation, solution identification, solution implementation and evaluation) participatory community-action cycle in 24 intervention clusters. ${ }^{9}$ The basic cycle has also been described elsewhere by HowardGrabmann (2002) and Morrison (2005). ${ }^{10,11}$ The quantitative data was taken from two of the meetings in this cycle meeting three, where groups identified neonatal health problems experienced in the community (defined as those affecting babies during delivery, immediately after birth and up to one month after birth) and meeting five where groups prioritised the five maternal and neonatal health problems they felt were most important in the community (groups generally used the criteria of severity and commonness when establishing the importance of a problem). ${ }^{9}$ Discussions were guided by trained local facilitators and used participatory tools and picture cards to stimulate and clarify discussions. After each of these meetings the groups listed the neonatal problems identified and prioritized on monitoring forms. 3484 and 3338 women, respectively, participated in meetings three and five in 204 women's groups. These women ranged in age from 15 to 78 years of age. Most women involved in identifying neonatal health problems also participated in prioritising the problems, but a small proportion of women were only involved in one or other of these activities due to changes in group membership over time. Qualitative data was collected from focus groups, conducted with six women's groups, and interviews, conducted with 22 individuals living in women's group communities but not attending groups. The women's groups selected came from clusters purposively sampled to represent the range and diversity of characteristics across all clusters, such as socio-economic status, tribe, intervention combination, urban-rural mix and individual characteristics of local facilitators. 67 women took part in these discussions, and ranged in age from 15 to 50 years. All women in the focus groups had also participated in discussions to identify and prioritise neonatal health problems. The 22 interview respondents were selected from villages in clusters also purposively sampled to ensure that they represented the range and diversity across all clusters. The interviewer convenience sampled these respondents on arrival at the sampled villages. The respondents ranged in age from 23 to 54 years, 14 of them were female and 8 were male. Most respondents (16) did not have any specific roles in the community but three were village headmen, two were headman advisers and one was a traditional birth attendant.

\section{Data processing and analysis}

Quantitative data from the monitoring forms for meetings three and five was available from all 204 groups that conducted these meetings. In problem identification, 133 of these groups categorised problems by period (during delivery, immediately after delivery and up to one month after birth) and 71 did not. The groups identified a number of problems directly and also a number of signs and symptoms of problems. Final lists of neonatal and infant health problems were generated with the assistance of two Malawian paediatricians (PK and $\mathrm{CM}$ ) and one British paediatrician (AC). The data on prioritised problems was transformed to reflect their relative ranking as groups ranked problems higher when they felt they were more important. To indicate this ranking, problems were given a score by multiplying the number of groups who prioritised the problems by three if the highest priority problem, two if the second highest and 1 if the lowest. The scores were then added together (maximum possible score $204 \times 3=612$ ). The data on problems identified and problems prioritised was analysed with descriptive statistics to assess distributions and trends using SPSS 16.0.

The interviews and focus groups were audio recorded and translated into English, from Chichewa, by a bilingual speaker. To ensure conceptual, grammatical and syntactical

equivalence, translations were reviewed by the researcher who collected the information, the translator (both bilingual Chichewa-English speakers) and the lead researcher (MR -

English speaker). The team made joint decisions about the best terms to use. Data was subsequently transcribed and imported into MAXqda2007, where a system of codes and

memos was developed. This method sought to develop an analytical framework based on the data by coding and highlighting pertinent excerpts that showed emerging themes. ${ }^{12}$ In an iterative process, the analysis was then refined, ensuring that themes built up were cross-checked with other data within and then between transcripts, to test and improve the validity of emerging explanations. The qualitative data was also used to interpret and contextualise the quantitative data.

Verbal consent was given by the groups for the data collected through the monitoring forms to be used to explore and assess the implementation of the groups and also given by the interview and focus group respondents to participate and, separately, to be audio recorded.

\section{Results}

\section{Women's groups definitions of the neonatal health period}

The groups identified and prioritised neonatal health problems, defined as those affecting babies during delivery, immediately after delivery and up to one month after birth.

However, the groups also identified problems generally considered to affect infants rather than neonates. Evidence suggests that this is because the concept of a neonate is not defined consistently or in accordance with any epidemiological definition in the communities involved. Indeed, although most respondents in the interviews and focus groups stated that a neonate was a "newly born child" or a "child just after birth"; exploration of the concept revealed that this period was considered to last from birth up to anything from one month to five years of age. Furthermore, most definitions were not time related but instead considered the period to last from birth up to the achievement of

a milestone such as the child standing, walking or stopping breastfeeding. These milestones were considered to overlap with a stage at which the child had gathered specific knowledge that differentiated it from a neonate who lacked this knowledge.

Interviewer: How about if it could be said, this child is a newborn, what does this mean?

Respondent: I can say, she cannot be in a position to know things... she [the newborn] does not have the knowledge. 


\section{Interview - Female community member - 35 years old}

An added complexity is that some respondents did not consider the neonatal period to start from birth. A few of the respondents stated that for a period of time after birth the child is not yet considered a person and as such cannot be considered a neonate, or indeed an infant or a child. The respondents revealed that this period lasts from a few days up to one month after birth at which point the child is considered to have become a person.

This period is called "chikuta" (period of confinement) and is generally considered to come to an end after the umbilical cord has dropped off and the child can be carried on

the mother's back. It is often formalised by a ritual of 'warming' the child to make it human. At this stage the child can be considered a neonate for a further period of time or till another milestone is reached as discussed above.

She has reached the stage to say, she is really a person... but if she may die [before reaching this stage] can we say she is a newborn? Of course she is not a newborn.

\section{Focus group discussion - Women's group mem- bers}

\section{Neonatal and infant health problems identified}

The 204 women's groups identified a total of 85 different neonatal and infant health problems of varying degrees of severity. On average groups identified 15 problems (range 5 32). The most commonly identified problems were infection, asphyxia and tetanus (Table 1).

More than $90 \%$ of groups identified these problems and indeed almost all groups (197 - 97\%) identified infection. By far the most commonly identified form of infection was umbilical infection, which represented $53 \%$ of infections identified (this includes the problems: umbilical infection; swelling or weeping of the cord; and ulongolongo, which is a traditional name for a condition where the baby has black lines radiating from the umbilical stump) followed by eye infection (29\%), neonatal sepsis (13\%) and ear infection (5\%). More than three quarters of groups identified diarrhoea (163 $-80 \%)$, malaria $(158-78 \%)$ and respiratory tract infections (RTIs) $(157-77 \%)$. The other problems identified by more than half the groups were jaundice $(124-60.8 \%)$ and preterm baby $(108-53 \%)$. Only about one third of groups identified malnutrition $(80-39 \%)$ and hypothermia $(77-38 \%)$.

Asphyxia was by far the most commonly identified problem in the period during delivery, identified by almost nine in ten groups $(118-89 \%)$ (table 2$)$. All other problems identified in this period were identified by less than one third of groups. The second and third most commonly identified problems in the intrapartum period were malpresentation $(36-27 \%)$ and preterm baby $(25-19 \%)$. The two most commonly

identified problems in the period immediately after birth, tetanus $(70-53 \%)$ and infection $(66-50 \%)$, were identified by about half of the groups. One third also identified jaundice $(32-24 \%)$ in this period. Over half the groups identified malaria $(82-62 \%)$, infection $(81-61 \%)$, diarrhoea and RTIs (both $69-52 \%$ ) in the period up to one month after birth making them the most commonly identified problems in this period.

Neonatal and infant health problems prioritised as most important
The groups were encouraged to prioritise both maternal and neonatal problems amongst these five but how they chose to split the selection was their own decision. The groups prioritised 17 different neonatal problems with 15 groups (7\%) prioritising one problem, 186 groups (90\%) prioritising two problems and three groups $(1 \%)$ prioritising three problems. A further three groups (1\%) did not prioritise any neonatal problems and these have been excluded from the analysis. This shows that the majority of groups chose to prioritise more maternal than neonatal problems.

Evidence from the interviews and focus groups conducted shows that this may not be due to a lower status given to neonatal problems. Instead, it may be due to the difficulties experienced in identifying neonatal compared to maternal problems and assessing their severity as children in this age group are not able to clearly explain what they are feeling and how strongly. Some respondents from women's group communities who did not attend groups felt that identifying neonatal problems required specialist knowledge unavailable at the community level.

For the problems found in newborns, since they are children, therefore they don't talk saying such-and-such a part is aching. Therefore we cannot know what problem this child has. Maybe we can only see her crying...no, about the problems faced by maybe the newborn child, the doctors are the ones who can know such problems but as for this village a simple community member cannot know whether this newborn baby, her problems are $A, B$ or $C$.

\section{Interview - Female community member -50 years old}

The problem prioritised as most important was diarrhoea, which scored 203 out of a possible 612 (figure 1). Diarrhoea was ranked in the top five health problems by one third of groups (38\%), which is the same as infection (38\%) but which scored lower (177) and was ranked second. Preterm baby, tetanus and malaria also all scored over 100 and were ranked third (155 - ranked in the top five problems by $29.9 \%$ of groups), fourth $(146-28 \%)$ and fifth $(110-21 \%)$ respectively. Almost one in five groups (18\%) identified asphyxia (95), which was ranked sixth, among the top five problems prioritised. The remaining problems prioritised scored less than 40 and were prioritised amongst the top five problems by less than $10 \%$ of groups. They were RTIs (rank: seventh; score: 40; percentage of groups: $8 \%$ ), hypothermia (rank: eighth; score: 39; percentage of groups: $7 \%$ ), jaundice (rank: ninth; score: 17; percentage of groups: $3 \%$ ), convulsions (rank: tenth; score: 4; percentage of groups $1 \%$ ) and malnutrition (rank: eleventh; score: 3; percentage of groups: $1 \%$ ).

The health problems were grouped into those considered to predominantly affect neonates (preterm baby, asphyxia, infection, tetanus, jaundice and hypothermia) and those considered to predominantly affect infants (diarrhoea, malaria, RTIs, and malnutrition). Convulsions were considered to affect both neonates and infants. Using this categorisation $38 \%$ (76 group) of groups prioritised both neonatal and infant health problems. 49\% (98 group) prioritised solely problems considered to affect predominantly neonates while $13 \%$ (26 groups) prioritised solely problems considered to affect predominantly infants. 


\begin{tabular}{|c|c|c|c|}
\hline \multicolumn{4}{|l|}{ All periods $(\mathrm{n}=204)$} \\
\hline Rank $\quad$ Problems identified & & Problem inferred & $\mathrm{n}(\%)$ \\
\hline $\begin{array}{l}1 \text { Neonatal sepsis, ear infection, eye infection, and umbilic } \\
\text { infection (including ulongolongo and swelling or weeping } \\
\text { of cord stump) } \\
2 \text { Drinking amniotic fluid, born in amniotic sack, born } \\
\text { wrapped in umbilical cord and umbilical delivered before } \\
\text { baby } \\
3 \text { Tetanus } \\
4 \text { Diarrhoea } \\
5 \text { Malaria } \\
6 \text { Pneumonia, cough, sore throat, TB and flu } \\
7 \text { Yellow fever and jaundice } \\
8 \text { Preterm baby } \\
9 \text { Malnutrition } \\
10 \text { Hypothermia }\end{array}$ & $\begin{array}{l}\text { Asphyxia } \\
\text { Tetanus } \\
\text { Diarrhoea } \\
\text { Malaria } \\
\text { RTIs } \\
\text { Jaundice } \\
\text { Preterm baby } \\
\text { Malnutrition } \\
\text { Hypothermia }\end{array}$ & Infection & $\begin{array}{l}189(92.6) \\
186(91.2) \\
163(79.9) \\
158(77.5) \\
157(77.0) \\
124(60.8) \\
108(52.9) \\
80(39.2) \\
77(37.7)\end{array}$ \\
\hline
\end{tabular}

Table 1: The ten neonatal and infant health problems most commonly identified by women attending MaiMwana women's groups in Mchinji District across all periods

\section{Discussion}

Women's groups in Malawi identified and subsequently prioritised diarrhoea, infection, preterm birth, tetanus, malaria, asphyxia, RTIs, hypothermia, jaundice, convulsions and malnutrition as the most important problems facing neonates and infants in their communities.

The results suggest that women in Malawi do not define the neonatal period consistently or in line with the epidemiological definition. This is not surprising as the epidemiological definition of 28 days is arbitrary and does not relate to any

developmental milestone or clinical pattern. In general, to women in Malawi, the neonatal period definition encompasses the infant period and even the under-five period.

As a result, although the groups engaged in identifying and prioritising neonatal problems they also identified and prioritised problems that considered to predominantly affect infants rather than neonates: diarrhoea, malaria, RTIs and malnutrition. However, a review of the problems identified by the groups by period (during delivery, immediately after delivery and up to one month after birth) shows that groups did not identify any of these problems in the period during delivery and the problems that they did identify most commonly in this period (asphyxia, malpresentation, preterm birth, stillbirth and infection) are indeed considered to affect children of this age. In addition, asphyxia, malpresentation, preterm birth and stillbirth, which can be considered to only affect children in this period, were not commonly identified in the other periods later after birth. This suggests that the women have a very clear understanding of the problems affecting children in the period defined epidemiologically as the intrapartum period or perinatal period. This is also true of the period immediately after birth (epidemiologically defined as the early neonatal period or perinatal period) where the women most commonly identified problems, which are indeed predominantly seen in children of this age: tetanus;

infection; jaundice; hypothermia; and convulsions. However RTIs, also identified in this period, are not usually seen in children of this age. It is in the period from about seven days up to one month after birth (epidemiologically defined as the late neonatal period) that the groups identified a number of problems generally observed predominantly in

infants, in particular malaria, diarrhoea and RTIs. This suggests that it is predominantly in this period that the local definitions of neonatal and infant overlap.

This study forms part of the women's group intervention process evaluation which aims to explore the factors that may help to understand and explain impact, make a priori

hypotheses on the basis of these findings and test these hypotheses with the impact data where sufficient sub-group power exists. Thus, these issues of definition are of interest as they potentially have implications for the impact being observed through the cluster randomised controlled trial being conducted of the women's group intervention. The

original primary outcomes for this trial were maternal, perinatal and neonatal mortality and the secondary outcomes include maternal, perinatal and neonatal care and careseeking practices. Infant mortality and care and care-seeking behaviour were subsequently added and the findings of this study support their inclusion as four of the ten problems most commonly identified by groups are considered to affect predominantly infants as is the problem prioritised as most important by groups, diarrhoea.

Furthermore, one in four groups (38\%) chose to prioritise and address infant as well as neonatal problems and 13\% of groups chose to prioritise and address only infant problems. This study suggests that it is important for policy-makers to consider the issues of the definition of the neonatal period in design and evaluation of targeted community mobilisation interventions for neonatal health. If infant outcomes are not included in the monitoring of such interventions, the true population impact for child health might be underestimated, particularly in sub-Saharan African countries, where postneonatal mortality makes up a much larger proportion of infant deaths than in Asia.

The results suggest that the perceptions of women's groups closely reflect epidemiological prevalence data. Statistical modeling of direct causes of neonatal death identified that preterm birth (28\%), sepsis/pneumonia (26\%), asphyxia $(23 \%)$, tetanus and congenital abnormalities (both 7\%), and diarrhoea (3\%) accounted for most deaths. ${ }^{13}$ WHO worldwide estimates for under-fives can be interpolated for causes of 
death in infants and suggest that the most important causes are: pneumonia (19\%); diarrhoea (17\%); malaria $(8 \%)$; measles (4\%); and HIV/AIDS and injuries (both 3\%). ${ }^{14}$ The data presented in this study is of perception rather than prevalence. As a result, this comparison must be viewed with caution and should not bring into question the pragmatic validity of the data presented..$^{15}$ The perceptions of women's groups are intrinsically valuable precisely because they are their own views and also because they represent the first step in a process of taking control of these issues and addressing them.

However, the similarity between the problems identified and prioritised by the women's groups and those from epidemiological studies confirms the importance of these

problems to policy makers. More importantly where these differ they challenge the views taken for granted by policy makers and warrant further investigation. ${ }^{16}$ For example, women prioritised tetanus very highly, because if its extreme severity, although it is not considered to be very prevalent in Malawi. An exploration of people's perceptions and experiences in relation to tetanus may reveal gaps and opportunities in neonatal and infant health policy and strategy in Malawi. We are aware of the limitations of medical knowledge and practice and it is through the exploration of and challenge by lay knowledge that these limitations can be addressed and that the wisdom of rural Malawian women is revealed. ${ }^{17}$

The Malawi 2004 DHS spotlights three problems prioritised by the groups as major causes of morbidity and mortality in young children in Malawi. The report states that $19 \%$, $22 \%$ and $37 \%$ of children aged under-five had suffered from RTIs, diarrhoea and malaria, respectively, at some point in the two weeks prior to the survey ${ }^{1}$ The report also states that a gap exists in communities in relation to knowledge of the importance of these problems and knowledge and implementation of appropriate responses. ${ }^{1}$ This study suggests that community mobilisation may provide an effective solution to this situation as women's groups can collectivise knowledge and thus hold a developed understanding of neonatal and infant health problems and their importance. In addition, the groups have subsequently managed to catalyse their communities into collective action to address these problems. For example, on the basis of the problems identified and prioritised communities in Malawi have engaged in a broad range of water, sanitation and hygiene activities, they have developed and implemented a system of community-based ITN distribution in collaboration with the district hospital and they have lobbied for and are managing bicycle ambulances to take children the nearest health facility when they are sick. This extends the findings from a previous study that found rural women in Malawi, collectively sharing experiences, exhibited a developed understanding of maternal health risks and problems and motivation to address them.' This study suggests that they also have a similar understanding of and motivation to address neonatal and infant health risks and problems. Together these studies confirm that communities have a role to play in policy and strategy development and furthermore that drawing on the collective capacities within communities to solve problems and take control of their own health might be an effective strategy for reducing mortality, whether maternal, neonatal or infant.

\section{References}

1 National Statistics Office Malawi, OCR Macro. Malawi Demographic and Health Survey 2004. Calverton, Maryland: NSO and OCR Macro, 2005.

2 United Nations. The Millennium Development Goals Report 2009. United Nations, 2009.

3 Malawi Ministry of Health. Road map for accelerating the reduction of maternal and neonatal mortality and morbidity in Malawi. Malawi Ministry of Health; 2005.

4 Howard-Grabmann L, Snetro G. How to mobilize communities for health and social change. Health Communications Partnership, USAID, 2003.

5 Manandhar D, Osrin D, Shreshtha B, et al. Effect of a participatory intervention with women's groups on birth outcomes in Nepal: clusterrandomized controlled trial. Lancet 2004; 364: 970-79.

6 Tripathy PK, Nair N, Barnett S, Mahapatra R, Borghi J, Rath S, Rath S, Gope R, Mahto D, Prost A, Costello AM. Effect of a participatory intervention with women's groups on birth outcomes in Jharkhand and Orissa, India: the Ekjut trial. [forthcoming]

7 National Statistics Office Malawi. 2008 Population and Housing Census: Preliminary Report. National Statistics Office Malawi, 2008.

8 World Bank. World Development Report: from plan to market. Oxford University Press, 1996.

9 Rosato M, Mwansambo CW, Kazembe PN, Phiri T, Soko QS, Lewycka S, Kunyenge BE, Vergnano S, Osrin D, Newell M-L, Costello AM de L. Women's groups' perceptions of maternal health problems in rural Malawi. Lancet 2006; 368: 1180-88

10 Howard-Grabmann L, Seone G, Davenport C. The Warmi Project: a participatory approach to improve maternal and neonatal health: an implementer's manual. Westport: John Snow International Mothercare Project, Save the Children, 2002.

11 Morrison J, Tamang S, Mesko N, et al. Women's health groups to improve perinatal care in rural Nepal. BMC Pregnancy Childbirth $2005 ; 5: 6$.

12 Lofland J, Lofland L. Analyzing social settings: a guide to qualitative observation and analysis. Wadsworth, 1995.

13 Lawn J, Cousens S, Zupan J. 4 million neonatal deaths: when? where? why? Lancet 2005; 365: 891-900.

14 Semba R, Bloem M. Nutrition and health in developing countries. Humana Press, 2008.

15 Kvale S. Interviews: an introduction to qualitative research interviewing. Thousand Oaks: Sage, 1996.

16 Malterud K. Symptoms as a source of medical knowledge: understanding medically unexplained disorders in women. Family Medicine Journal 2000; 32: 603-11.

17 Malterud K. Women's wisdom - a source of knowledge for medicine. Lancet 2006; 368 


\begin{tabular}{|c|c|c|c|}
\hline Rank & Problems identified & Problem inferred & $\mathrm{n}(\%)$ \\
\hline \multicolumn{4}{|c|}{ During delivery $(n=133)$} \\
\hline 1 & $\begin{array}{l}\text { Drinking amniotic fluid, born in amniotic sack, born } \\
\text { wrapped in umbilical cord and umbilical cord delivered } \\
\text { before baby }\end{array}$ & Asphyxia & $118(88.7)$ \\
\hline $\begin{array}{l}2 \\
3 \\
4 \\
5\end{array}$ & $\begin{array}{l}\text { Malpresentation } \\
\text { Preterm baby } \\
\text { Stillbirth } \\
\text { Neonatal sepsis, ear infection, eye infection and umbilical } \\
\text { infection (including ulongolongo and swelling or weeping } \\
\text { of cord stump) }\end{array}$ & $\begin{array}{l}\text { Malpresentation } \\
\text { Preterm baby } \\
\text { Stillbirth } \\
\text { Infection }\end{array}$ & $\begin{array}{l}36(27.1) \\
25(18.8) \\
14(10.5) \\
9(6.8)\end{array}$ \\
\hline \multicolumn{4}{|c|}{ Immediately after delivery $(n=133)$} \\
\hline $\begin{array}{l}1 \\
2\end{array}$ & $\begin{array}{l}\text { Tetanus } \\
\text { Neonatal sepsis, ear infection, eye infection and umbilical } \\
\text { infection (including ulongolongo and swelling or weeping } \\
\text { of cord stump) }\end{array}$ & $\begin{array}{l}\text { Tetanus } \\
\text { Infection }\end{array}$ & $\begin{array}{l}70(52.6) \\
66(49.6)\end{array}$ \\
\hline $\begin{array}{l}3 \\
4 \\
5\end{array}$ & $\begin{array}{l}\text { Yellow fever and jaundice } \\
\text { Pneumonia, cough, sore throat, TB and flu } \\
\text { Hypothermia } \\
\text { Convulsions }\end{array}$ & $\begin{array}{l}\text { Jaundice } \\
\text { RTIs } \\
\text { Hypothermia } \\
\text { Convulsions }\end{array}$ & $\begin{array}{l}32(24.1) \\
31(23.3) \\
27(20.3)\end{array}$ \\
\hline \multicolumn{4}{|c|}{ Up to one month after birth $(n=133)$} \\
\hline $\begin{array}{l}1 \\
2\end{array}$ & $\begin{array}{l}\text { Malaria } \\
\text { Neonatal sepsis, ear infection, eye infection and umbilical } \\
\text { infection (including ulongolongo and swelling or weeping } \\
\text { of cord stump) }\end{array}$ & $\begin{array}{l}\text { Malaria } \\
\text { Infection }\end{array}$ & $\begin{array}{l}82(61.7) \\
81(60.9)\end{array}$ \\
\hline $\begin{array}{l}3 \\
5\end{array}$ & $\begin{array}{l}\text { Diarrhoea } \\
\text { Pneumonia, cough, sore throat, TB and flu } \\
\text { Tetanus }\end{array}$ & $\begin{array}{l}\text { Diarrhoea } \\
\text { RTIs } \\
\text { Tetanus }\end{array}$ & $\begin{array}{l}69(51.9) \\
39(29.3)\end{array}$ \\
\hline
\end{tabular}

\begin{tabular}{|r|r|r|r|}
\hline Problem prioritived & 1 & Rank (score) \\
\hline Diarrhoea & (203) & $2(177)$ \\
Infection & & & $3(155)$ \\
Preterm \\
Matanus
\end{tabular}

